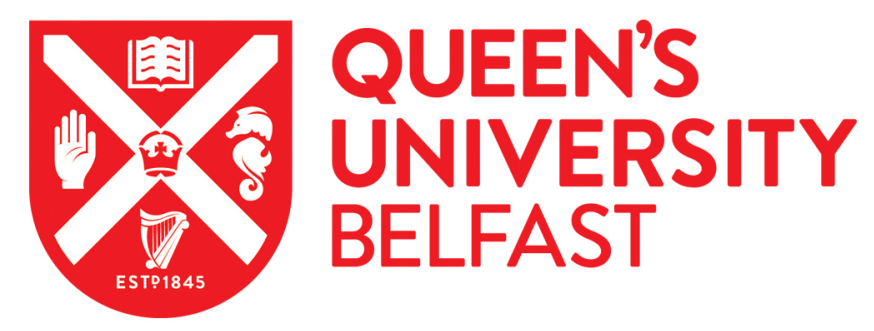

\title{
Prospective memory impairment in chronic heart failure
}

Habota, T., McLennan, S. N., Cameron, J., Henry, J. D., Ski, C. F., Thompson, D. R., \& Rendell, P. G. (2015). Prospective memory impairment in chronic heart failure. Journal of the International Neuropsychological Society, 21(3), 183-192. https://doi.org/10.1017/S1355617715000119

Published in:

Journal of the International Neuropsychological Society

Document Version:

Publisher's PDF, also known as Version of record

Queen's University Belfast - Research Portal:

Link to publication record in Queen's University Belfast Research Portal

Publisher rights

(c) 2015 The International Neuropsychological Society.

This work is made available online in accordance with the publisher's policies. Please refer to any applicable terms of use of the publisher.

\section{General rights}

Copyright for the publications made accessible via the Queen's University Belfast Research Portal is retained by the author(s) and / or other copyright owners and it is a condition of accessing these publications that users recognise and abide by the legal requirements associated with these rights.

Take down policy

The Research Portal is Queen's institutional repository that provides access to Queen's research output. Every effort has been made to ensure that content in the Research Portal does not infringe any person's rights, or applicable UK laws. If you discover content in the Research Portal that you believe breaches copyright or violates any law, please contact openaccess@qub.ac.uk. 


\title{
Prospective Memory Impairment in Chronic Heart Failure
}

\author{
Tina Habota, ${ }^{1}$ Skye N. McLennan, ${ }^{1}$ Jan Cameron, ${ }^{2}$ Julie D. Henry, ${ }^{3}$ Chantal F. Ski, ${ }^{2}$ David R. Thompson, ${ }^{2}$ AND \\ Peter G. Rendell ${ }^{1}$ \\ ${ }^{1}$ School of Psychology, Australian Catholic University, Melbourne, Australia \\ ${ }^{2}$ Centre for the Heart and Mind, Australian Catholic University, Melbourne, Australia \\ ${ }^{3}$ School of Psychology, University of Queensland, Brisbane, Australia \\ (Received September 16, 2014; Final Revision January 12, 2015; Accepted January 19, 2015; First Published Online March 30, 2015)
}

\begin{abstract}
Although cognitive deficits are common in patients with chronic heart failure (CHF), no study to date has investigated whether these deficits extend to the capacity to execute delayed intentions (prospective memory, PM). This is a surprising omission given the critical role PM plays in correctly implementing many important CHF self-care behaviors. The present study aimed to provide the first empirical assessment of PM function in people with CHF. The key dependent measure was a laboratory measure of PM that closely simulates PM tasks in daily life - Virtual Week. A group comparison design was used, with $30 \mathrm{CHF}$ patients compared to 30 demographically matched controls. Background measures assessing executive functions, working memory, and verbal memory were also administered. The CHF group exhibited significant PM impairment, with difficulties generalizing across different types of PM tasks (event, time, regular, irregular). The CHF group also had moderate deficits on several of the background cognitive measures. Given the level of impairment remained consistent even on tasks that imposed minimal demands on memory for task content, CHF-related difficulties most likely reflects problems with the prospective component. However, exploratory analyses suggest that difficulties with retrospective memory and global cognition (but not executive control), also contribute to the PM difficulties seen in this group. The implications of these data are discussed, and in particular, it is argued that problems with PM may help explain why patient engagement in CHF self-care behaviors is often poor. (JINS, 2015, 21, 183-192)
\end{abstract}

Keywords: Prospective memory, Chronic heart failure, Virtual Week, Executive functions, Retrospective memory, Cognitive functions

\section{INTRODUCTION}

Chronic heart failure $(\mathrm{CHF})$ is a clinical syndrome resulting most frequently from long-standing coronary heart disease (Braunwald, 2013). It is a complex condition characterized by structural dysfunction and weakening of the heart muscle which, in its most common form, impairs the ability of the left ventricle to either eject, or fill adequately, with blood to meet the body's needs (Krum, Jelinek, Stewart, Sindone, \& Atherton, 2011). The annual incidence of CHF approaches 10 per 1000 population in those over 65 years of age (LloydJones et al., 2002), with this age group accounting for more than $80 \%$ of CHF morbidity and mortality (Bui, Horwich, \& Fonarow, 2010). Despite significant improvements in the multidisciplinary management of CHF (Lindenfeld et al., 2010),

Correspondence and reprint requests to: Tina Habota, Australian Catholic University, School of Psychology, Locked Bag 4115, Fitzroy MDC, VIC 3065, Australia. E-mail: tina.habota@acu.edu.au most patients experience debilitating symptoms that impact on activities of daily living, quality of life, and mental health, contributing to frequent hospitalizations, and reduced wellbeing (Volz et al., 2011).

A frequent secondary complication of $\mathrm{CHF}$ is cognitive impairment. Cognitive deficits have been observed in as many as $50 \%$ of clinically stable outpatients, and up to $80 \%$ of hospitalized patients (Bennett \& Sauvé, 2003; Cameron et al., 2010; Pressler, 2008). The domains of cognition that are impaired most frequently are attention and concentration, memory, psychomotor speed, and executive control (Alosco et al., 2013; Vogels, Oosterman, et al., 2007; Vogels, Scheltens, Schroeder-Tanka, \& Weinstein, 2007), but other areas are also affected, including language, working memory, and visuospatial function (Kindermann et al., 2012; Pressler, Kim, Riley, Ronis, \& Gradus-Pizlo, 2010).

These cognitive difficulties appear to primarily be caused by damage to diffuse regions of the subcortical white matter, particularly in the frontal lobes, and to subcortical grey matter 
nuclei, particularly the thalamus, basal ganglia and brainstem (Artero et al., 2004; de Leeuw et al., 2001; Kalaria et al., 2004; Vogels, van der Flier, et al., 2007). Medial temporal and temporal-parietal regions are also vulnerable to grey matter loss (Almeida et al., 2012; Woo, Macey, Fonarow, Hamilton, \& Harper, 2003; Zuccalà et al., 1997). Collectively, these findings show that CHF patients display relatively frequent cerebral abnormalities in frontal and, to a lesser degree, temporal neural structures. This is important because these brain regions have been specifically implicated in prospective memory (PM; Braver \& Barch, 2002; Costa, Caltagirone, \& Carlesimo, 2011; Reynolds, West, \& Braver, 2009), which refers to the ability to remember to carry out intended plans at specific points in the future (Rendell \& Henry, 2009).

Surprisingly, this critical cognitive ability has not yet been examined in CHF patients. It is important to understand the nature and severity of PM difficulties in this population given that PM is implicated in a wide variety of functional behaviors (Ellis \& Freeman, 2008). In the present study, we were particularly interested to determine whether specific aspects of PM are differentially impaired. Given that frontal brain regions are amongst the most severely affected in CHF, and that these neural substrates are implicated in executive control operations, it might be anticipated that those aspects of PM that require control operations such as self-initiated retrieval, or strategic monitoring may be disproportionately affected.

A key distinction within PM task types is between eventbased and time-based tasks. Event-based tasks are triggered by event-based cues and require monitoring of the environment to detect the cues (Einstein \& McDaniel, 2005). For example, returning home in the afternoon (PM event) acts as a cue for taking a diuretic medication (PM task). Conversely, time-based tasks are performed at a specific time, or once a specific amount of time has elapsed; for example, taking medication (PM task) at 9 AM (Einstein \& McDaniel, 2005). As time-based PM tasks require more strategic monitoring and self-initiated control processes than event-based PM tasks (McDaniel \& Einstein, 2000), they may be particularly impaired in patients with CHF.

Another task distinction, emerging from research involving a computerized assessment paradigm known as Virtual Week, is between PM tasks that are regular and those that are irregular (Foster, Rose, McDaniel, \& Rendell, 2013). In this paradigm, regular tasks are frequently repeated and are well learned, while irregular tasks occur only once. Irregular tasks impose substantially greater demands on retrospective memory because they are not as well learned (Foster et al., 2013; Terrett et al., 2014). Foster et al. (2013) argue that a comparison of repeated versus one-off tasks is important, because it can clarify whether observed difficulties in PM reflect poor encoding of the task (the retrospective component) as opposed to difficulty initiating the task at the appropriate moment (the prospective component). Because of the particular involvement of frontal structures in CHF, any PM difficulties are unlikely to be explained entirely by the retrospective component, but are likely to also reflect deficits related to the prospective component.

The overarching goal of the present study was to provide the first empirical comparison of PM ability in people with $\mathrm{CHF}$ and demographically matched controls. It was predicted that people with CHF would show impaired PM performance, compared to controls, and that these impairments would be greater for time relative to event-based tasks, and for irregular relative to regular tasks.

\section{METHOD}

The study was approved by the Human Research Ethics Committees at Eastern Health and the Australian Catholic University. A detailed study protocol has been described in Habota et al. (2013).

\section{Participants}

The Chronic Heart Failure (CHF) group was recruited from a pool of participants taking part in the parent study $(n=96)$ (13 participants were paid AUD \$10 per hour, the rest were volunteers). To be eligible for the parent study participants had to have a documented diagnosis of CHF based on national guidelines; specifically, cardinal symptoms (fatigue) and clinical features of congestion (exertional dyspnea, lung crepitation), and objective evidence of cardiac impairment determined from echocardiography (Krum et al., 2006). All participants were outpatients actively engaged in a nurse-led CHF management program or CHF clinic, in one of three public hospitals in Metropolitan Melbourne, Australia. Participants were excluded if they resided in a residential aged high care facility, had a terminal diagnosis, a documented history of dementia, or could not read English. The screening and recruitment process for the CHF group is presented in Figure 1 .

We did not exclude people with psychiatric illness, but participants' global cognition was screened using the Addenbrooke's Cognitive Examination - Revised (ACE-R) (Mathuranath, Nestor, Berrios, Rakowicz, \& Hodges, 2000). Anyone who showed signs of potential dementia, as operationalized by a score lower than 82 , was excluded. There were no participants with head injury. The final sample of CHF patients consisted of 30 adults aged between 40 and 86 $(M=70.03 ; S D=11.88)$ who were predominantly male (63\%). CHF severity was assessed using the New York Heart Association (NYHA) classification based on symptoms of breathlessness with varying degrees of activities, ranging from no symptoms with moderate activities (Class I), to severe symptoms at rest (Class IV). The first two categories represent no or mild CHF symptoms, and the last two categories represent moderate or severe symptoms. As shown in Table 1, most participants $(70 \%)$ had relatively mild CHF symptoms (functional classification I or II). Participants with left ventricular dysfunction (i.e., 70\% systolic), and ischemic $(50 \%)$ heart failure were dominant. On average, participants 


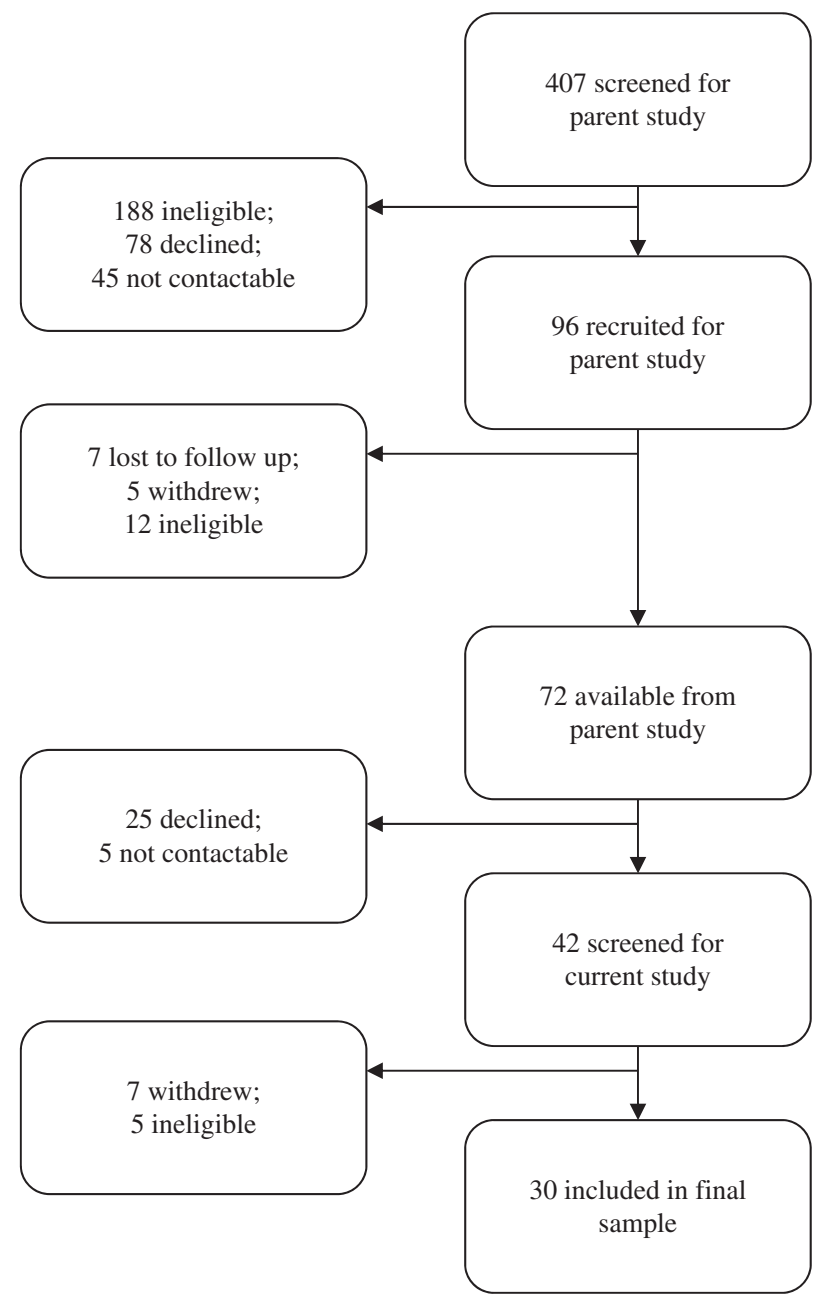

Fig. 1. Screening and recruitment process of the CHF group. The 12 ineligible participants had not yet reached the 3-month delay period (discussed in procedure section) during which the study was being conducted.

had a moderate level of comorbid disease burden (Charlson Comorbidity Index mean $=3.17$ ). Notably, four had moderate to severe renal disease, and time since initial diagnosis was almost 3 years $(M=33.19$ months; $S D=55.03)$. Excluded or ineligible participants from the pool of 96 did not differ significantly from the final sample on age, gender, years of education, or NYHA classification.

The control group was recruited from the general community (13 participants were paid AUD $\$ 10$ per hour, the rest were volunteers). Potential participants were excluded if they reported a history of CHF or neurological disease, had received treatment during the past three months for an acute cardiovascular problem, or could not read English. Thirtythree participants were initially recruited, but two were excluded due to cognitive difficulties (one based on a score below 82 on the ACE-R, and one because they did not understand the instructions of the primary measure). A further participant withdrew before completing the primary measure. Therefore, the final control group consisted of 30 adults. The control group did not significantly differ from the
Table 1. Clinical characteristics of the CHF group

\begin{tabular}{lr}
\hline \hline Health characteristics & $\%$ \\
\hline NYHA classification & \\
Class I & 6.7 \\
Class II & 63.3 \\
Class III & 26.7 \\
Class IV & 3.3 \\
Heart failure type & \\
Systolic & 70.0 \\
Diastolic & 13.3 \\
Mixed & 10.0 \\
Unspecified & 6.7 \\
Heart failure etiology & \\
Ischemic & 50.0 \\
Non ischemic & 30.0 \\
Idiopathic & 3.3 \\
Other & 16.7 \\
\hline \hline
\end{tabular}

Notes. NYHA = New York Heart Association.

CHF group in gender distribution (57\% male vs. 63\% male; $\left.\chi^{2}(1)=.28 ; p=.597\right)$. As shown in Table 2 , there was a trend toward higher proportions of cardiac risk factors in the CHF group, but these group differences were not significant (all $p \mathrm{~s}>.083$ ). Table 2 also shows that the two groups were closely matched in age, education, and estimated IQ as indexed by the National Adult Reading Test (Nelson, 1982).

\section{Procedure}

At the time of recruitment into the parent study, demographic and health related data (presented in Table 1) were collected using patient self-report and by reviewing medical records. After a delay of approximately 3 months, to ensure that participants were medically stable, all other measures were administered individually in a 3-hr session. The ACE-R was administered first, followed by Virtual Week, and then the remaining cognitive measures. CHF health characteristics were not reassessed at this time.

\section{Design}

A mixed factorial, matched group comparison design was used. Group (CHF, control) was the between-groups independent variable. The two within-group variables were $P M$ cue (eventbased, time-based), and PM task (regular, irregular).

\section{Measures}

\section{Global cognition}

Addenbrooke's Cognitive Examination - Revised (Mathuranath et al., 2000) was used to identify and exclude participants with possible dementia.

Analyses were based on raw scores for all measures, except for the National Adult Reading Test and the Hayling Sentence Completion Test, which were converted to scaled scores. 
Table 2. Participant characteristics

\begin{tabular}{|c|c|c|c|c|c|c|c|c|c|}
\hline & \multicolumn{3}{|c|}{ CHF group } & \multicolumn{3}{|c|}{ Control group } & \multirow[b]{2}{*}{$\chi^{2}$} & \multirow[b]{2}{*}{$p$} & \\
\hline & $n$ & $\%$ & & $n$ & $\%$ & & & & \\
\hline \multicolumn{10}{|l|}{ Cardiac risk factors $(\%)$} \\
\hline Hypercholesterolemia & 13 & $43.3 \%$ & & 11 & $36.7 \%$ & & 0.41 & .523 & \\
\hline Hypertension & 20 & $66.7 \%$ & & 14 & $46.7 \%$ & & 3.00 & .083 & \\
\hline Smoking & 11 & $36.7 \%$ & & 9 & $30.0 \%$ & & 0.41 & .520 & \\
\hline Diabetes & 5 & $16.7 \%$ & & 4 & $13.3 \%$ & & 0.17 & 677 & \\
\hline Obesity & 6 & $10.0 \%$ & & 2 & $6.7 \%$ & & 0.26 & 612 & \\
\hline Demographic (M) & & $M$ & $S D$ & & $M$ & $S D$ & $t$ & $p$ & $d$ \\
\hline Age (years) & 30 & 70.03 & 11.88 & 30 & 69.93 & 5.96 & 0.04 & .967 & 0.01 \\
\hline Education (years) & 30 & 11.13 & 3.44 & 30 & 12.08 & 2.89 & 1.16 & .252 & 0.30 \\
\hline Estimated IQ & 29 & 111.93 & 6.78 & 30 & 114.54 & 5.31 & 1.65 & .105 & 0.43 \\
\hline \multicolumn{10}{|c|}{ Global cognition and mental health } \\
\hline ACE-R & 29 & 90.79 & 4.64 & 30 & 93.07 & 4.00 & 2.02 & $.048^{*}$ & 0.53 \\
\hline Anxiety (HADS) & 29 & 6.10 & 3.52 & 30 & 6.53 & 3.88 & 0.45 & .658 & 0.12 \\
\hline Depression (HADS) & 29 & 5.00 & 2.83 & 30 & 4.17 & 3.03 & 1.10 & .280 & 0.28 \\
\hline \multicolumn{10}{|l|}{ Executive functions } \\
\hline Cognitive flexibility (TMT) & 26 & 71.85 & 34.15 & 29 & 58.42 & 32.61 & 1.49 & .142 & 0.40 \\
\hline Inhibition (Hayling) & 28 & 3.11 & 1.93 & 26 & 5.42 & 1.47 & 4.93 & $<.001^{* * * *}$ & 1.35 \\
\hline Initiation (Verbal fluency) & 30 & 29.60 & 6.28 & 30 & 33.10 & 6.93 & 2.05 & $.045^{*}$ & 0.98 \\
\hline Working memory (DS) & 27 & 17.70 & 3.16 & 30 & 19.63 & 4.67 & 1.84 & .071 & 0.48 \\
\hline \multicolumn{10}{|l|}{ Verbal memory (RAVLT) } \\
\hline Immediate recall & 26 & 41.31 & 8.48 & 28 & 48.89 & 8.09 & 3.36 & $.001^{* *}$ & 0.91 \\
\hline Delayed recall & 24 & 8.96 & 2.39 & 28 & 10.04 & 2.85 & 1.46 & .149 & 0.41 \\
\hline Recognition & 23 & 13.22 & 1.35 & 28 & 13.89 & 1.03 & 2.03 & $.048^{*}$ & 0.56 \\
\hline
\end{tabular}

Note. Effect sizes: small $=0.2 ;$ medium $=0.5 ;$ large $=0.8($ Cohen, 1988$)$.

$* p<.05$.

${ }^{* * *} p<.01$.

$* * * 0.001$

ACE-R = Addenbrooke's Cognitive Examination - Revised; $d=$ Cohen's $d$ index of effect size; DS = Digit Span; HADS = Hospital Anxiety Depression Scale; RAVLT $=$ Rey Auditory Verbal Learning Test; TMT $=$ Trail Making Test $(\mathrm{B}$ minus A).

\section{Background Measures}

\section{General intelligence}

The National Adult Reading Test (Nelson, 1982) was used to index premorbid intelligence (IQ). Estimated IQ was calculated using the formula provided in the administration manual (Nelson, 1982).

\section{Psychopathology}

The Hospital Anxiety and Depression Scale (Zigmond \& Snaith, 1983) was used to screen for symptoms of anxiety and depression. The level of emotional symptomology was calculated separately for anxiety and depression (seven items each).

\section{Executive function - cognitive flexibility}

The Trail Making Test (Reitan, 1992) was used to assess cognitive flexibility. It is a pencil and paper test consisting of two parts. Part A, required participants to draw lines to connect circles that were numbered consecutively. Part B required participants to connect circles that were numbered or lettered, alternating between the numeric and alphabetic sequences. The Trails B minus Trails A difference score was used as a measure of cognitive flexibility (Lamberty, Putnam, Chatel, Bieliauskas, \& Adams, 1994).

\section{Executive function - inhibition}

The Hayling Sentence Completion Test (Burgess \& Shallice, 1996) was used to assess cognitive inhibition. The key condition required participants to suppress their prepotent response when completing a sentence. A total score was obtained by tallying errors and time taken (in seconds) to complete the task.

\section{Executive function - initiation}

Verbal fluency was extracted from the ACE-R and used as a measure of cognitive initiation. Both phonemic and categorical fluency were assessed. For the former, participants were required to orally generate as many words beginning with the letter $\mathrm{P}$ as they could within $1 \mathrm{~min}$. For the latter, participants were required to name as many animals as they could within $1 \mathrm{~min}$. A composite verbal fluency score was used.

\section{Working memory}

The Digit Span subtest from the Wechsler Adult Intelligence Scale-IV (Wechsler, 2008) was used to measure working 
memory. Participants were verbally presented with a string of numbers (e.g., 7-2-8-6) and were required to remember and repeat these numbers in a specific order, either forward (e.g., 7-2-8-6) or backward (e.g., 6-8-2-7). A single composite score was used to index this construct.

\section{Verbal memory}

The Rey Auditory Verbal Learning Test (Rey, 1958) was used to measure verbal memory and provided a measure of immediate recall, delayed recall, and recognition. The examiner read aloud a list of 15 words. Participants were required to repeat all the words they could remember, in any order. This procedure was carried out five times. After a 20-min delay, participants were asked to recall as many words as possible. A recognition test was then administered where participants were presented with a list of 30 words and were asked to identify as many of the list words as possible.

\section{Prospective memory}

A shortened version of Virtual Week (Rendell \& Craik, 2000) was used to assess PM (for a review see, Rendell \& Henry, 2009). Virtual Week is a computerized board game that simulates a week of everyday activities. Virtual Week has been used widely within PM research and has robust psychometric properties (Rendell \& Henry, 2009; Rose, Rendell, McDaniel, Aberle, \& Kliegel, 2010). It is also sensitive to differences between clinical and normal populations (Rendell \& Henry, 2009).

In the present study (for detailed description see, Habota et al., 2013), participants used a computer mouse to move a token around a computerized representation of a board-game board after rolling a die. Each lap of the board represented one virtual day. At the beginning of each "day," they were given a list of PM tasks that they had to remember to action. As participants moved around the board, a series of ongoing activities were presented in the form of "events." At some of these events, participants had to remember to perform a PM task. For example, at the beginning of the game, participants were asked to remember to "drop in the dry cleaning" (PM task) when "shopping." As they moved around the board, they were instructed at several points, to pick up an "event card." When they picked up the event card "shopping," which served as the task cue, they had to remember to action the PM task by clicking on a "perform task" button and selecting the correct task. Other PM tasks had to be performed at a specified time of day (e.g., "attend a meeting with a librarian at $3 \mathrm{PM}$ "). They were required to monitor a virtual clock on the screen (calibrated to the position of the token on the board) and perform the relevant task by clicking on the "perform task" button at the specified time period. The perform task button revealed a list of possible tasks for participants to select from, including distractor items.

Participants completed three virtual days; 1 day was a trial day to ensure that they understood the objectives of the game, and the following 2 days were test days. During each test day, participants were given eight tasks to remember to perform.
Four tasks were regular, each occurring two times (take medication at the "breakfast" and "dinner" event cards, and take the asthma inhaler at two virtual times of day, 11 AM and 9 PM). Four tasks were irregular, each occurring only once (two event-based tasks and two time-based tasks).

Responses were counted separately for each possible response type (correct, missed, little late, late, little early, and early) and were expressed as a proportion of the total number of PM tasks (16 tasks, eight per virtual day) in each of the four categories: regular event, regular time, irregular event, and irregular time. Correct responses were defined as those performed within the window of time that started when the token arrived at (or went past) the target position on the board and closed when the dice was rolled again. Missed responses were defined as those that the participant did not remember at any time. Little late responses were defined as those that participants remembered after the correct criterion but before the next hour (on the virtual clock) for time-based tasks and before the next event card for event-based tasks. Lot late responses were defined as those made after the little late criterion and before the end of the virtual day. Little early were defined as responses made before the correct time and after the previous event card for the event-based tasks and 1 hour before the expected time for time-based tasks. Finally, lot early responses were defined as those made before the little early criterion and after the start of the virtual day.

\section{Recognition test of PM task content}

After completing each virtual day, participants' memory for the content of the PM tasks they were required to complete during that virtual day was tested. This recognition test provided an index of the retrospective component. Participants were presented with a list of PM tasks on the computer screen (e.g., take medication), which they had to match with the corresponding PM cue (e.g., at breakfast and dinner) from another list. The sample size for this measure was smaller (CHF $n=19$; controls $n=24)$ than the others $(n=30)$ due to clerical error. Importantly, missing value analyses for all variables showed that data was missing at random.

\section{RESULTS}

\section{Participant Characteristics}

As shown in Table 2, while the CHF group generally performed worse than controls on all eight cognitive tests, differences were only significant for cognitive inhibition, cognitive initiation, immediate recall, recognition, and global cognition. The two groups also did not differ in negative affect.

\section{Analysis of Prospective Memory Accuracy}

The dependent variable, PM performance, was expressed as the proportion of Virtual Week tasks completed correctly for each of the four categories of tasks: regular event, regular 
Table 3. PM accuracy: Mean $(S D)$ proportion of PM tasks executed at different time points

\begin{tabular}{|c|c|c|c|c|c|c|c|}
\hline Group & PM task type & Proportion correct & Missed & Little late & Lot late & Little early & Lot early \\
\hline \multirow[t]{4}{*}{$\mathrm{CHF}$} & Regular event & $.53(.41)$ & $.23(.30)$ & $.07(.15)$ & $.15(.22)$ & $.02(.09)$ & $.00(.00)$ \\
\hline & Regular time & $.63(.32)$ & $.19(.32)$ & $.12(.17)$ & $.03(.10)$ & $.01(.05)$ & $.04(.12)$ \\
\hline & Irregular event & $.57(.31)$ & $.23(.27)$ & $.05(.12)$ & $.03(.11)$ & $.02(.06)$ & $.11(.17)$ \\
\hline & Irregular time & $.33(.30)$ & $.39(.33)$ & $.07(.11)$ & $.16(.18)$ & $.02(.06)$ & $.03(.09)$ \\
\hline \multirow[t]{4}{*}{ Control } & Regular event & $.69(.33)$ & $.08(.18)$ & $.08(.17)$ & $.08(.15)$ & $.06(.13)$ & $.00(.00)$ \\
\hline & Regular time & $.66(.32)$ & $.11(.20)$ & $.13(.16)$ & $.02(.06)$ & $.03(.09)$ & $.06(.14)$ \\
\hline & Irregular event & $.68(.29)$ & $.18(.16)$ & $.04(.12)$ & $.01(.05)$ & $.04(.09)$ & $.06(.13)$ \\
\hline & Irregular time & $.53(.31)$ & $.26(.23)$ & $.08(.16)$ & $.10(.16)$ & $.01(.05)$ & $.03(.10)$ \\
\hline
\end{tabular}

Notes. PM task (regular, irregular) and PM cue (event-based, time-based) were within-group independent variables for the PM measure, Virtual Week. Proportion correct $=$ executed at correct time; Missed = missed altogether; Little late $=$ executed little late; Lot late = executed very late; Little early = executed little early; Lot early = executed very early.

time, irregular event, and irregular time (Table 3). Data were analyzed with a $2 \times 2 \times 2$ mixed analysis of variance (ANOVA) with the between-subjects variable of group (CHF, control), and the within-subjects variables of PM task (regular, irregular) and PM cue (event-based, time-based). Group did not interact with any of the variables (all $F$ s $\leq .94$; $p s \geq .337)$ but the main effect of group approached significance $\left(F(1,58)=3.76 ; p=.057 ; \eta_{\mathrm{p}}{ }^{2}=.06\right)$; there was a trend toward people with $\mathrm{CHF}(M=.51 ; S D=.35)$ performing more poorly than controls $(M=.64 ; S D=.31)$.

There were also main effects of $P M$ task $(F(1,58)=11.01$; $\left.p=.002 ; \quad \eta_{\mathrm{p}}^{2}=.16\right)$, and $P M$ cue $(F(1,58)=5.55$; $\left.p=.022 ; \eta_{\mathrm{p}}^{2}=.09\right)$, and a two-way interaction between $P M$ task and $P M$ cue $\left(F(1,58)=15.23 ; p<.001 ; \eta_{\mathrm{p}}{ }^{2}=.21\right)$. For irregular tasks, all participants performed worse on timebased $(M=.43 ; S D=.31)$ than event-based tasks $(M=.62$; $S D=.30),\left(F(1,58)=23.00 ; p<.001 ; \eta_{\mathrm{p}}{ }^{2}=.28\right)$, but time and event did not differ for regular tasks $(F=.38 ; p=.543)$. Further tests of simple effects showed that participants were worse on irregular $(M=.43 ; S D=.31)$ than regular $(M=.64 ; S D=.32)$ for time-based tasks $(F(1,58)=32.81$; $\left.p<.001 ; \eta_{\mathrm{p}}{ }^{2}=.36\right)$, but irregular and regular did not differ for event-based tasks $(F=.03 ; p=.854)$.

\section{Analysis of Missed Prospective Memory Responses}

These analyses were then repeated for the proportion of tasks missed (rather than completed correctly). Group did not interact with any variables (all $F \mathrm{~s} \leq .20 ; p \mathrm{~s} \geq .660$ ), but there was a main effect of group $(F(1,57)=4.52 ; p=.038$; $\left.\eta_{\mathrm{p}}{ }^{2}=.07\right)$; the CHF group $(M=.26 ; S D=.31)$ missed more responses than the controls $(M=.16 ; S D=.21)$. There were also main effects of PM task $(F(1,57)=13.43$; $\left.p=.001 ; \quad \eta_{\mathrm{p}}^{2}=.19\right)$, and $P M$ cue $(F(1,57)=5.01$; $\left.p=.029 ; \eta_{\mathrm{p}}{ }^{2}=.08\right)$, and a two-way interaction between $P M$ task and $P M$ cue $\left(F(1,57)=7.79 ; p=.007 ; \eta_{\mathrm{p}}{ }^{2}=.12\right)$. Tests of simple effects showed that for irregular tasks, participants missed more time-based $(M=.33 ; S D=.29)$ than event-based

tasks $(M=.20 ; S D=.22),(F(1,57)=10.133 ; p=.002 ;$ $\left.\eta_{\mathrm{p}}{ }^{2}=.15\right)$, but time and event did not differ for regular tasks
$(F=.21 ; p=.648)$. Further tests of simple effects showed that participants missed more irregular $(M=.33 ; S D=.29)$ than regular $(M=.15 ; S D=.27)$ time-based tasks $(F(1,57)=23.32$; $\left.p<.001 ; \eta_{\mathrm{p}}{ }^{2}=.298\right)$, but regular and irregular did not differ for event-based tasks $(F=1.11 ; p=.298)$.

Table 3 displays the types of errors made by the CHF and control groups. The CHF group made more misses than other types of errors. However, in the control group, missed responses were less prominent among the error types. The number of errors was typically low. The two groups had similar proportions of little late, little early, and lot early, but the $\mathrm{CHF}$ group had more errors on the lot late category, at least for regular event-based tasks.

\section{Analysis of Memory for Task Content}

An ANOVA was conducted to assess the number of tasks recognized at the end of each day. The dependent variable was the proportion of the six PM tasks that participants correctly matched for each of the four categories of tasks: regular event, irregular event, regular time, and irregular time. Data were again analyzed with a $2 \times 2 \times 2$ mixed ANOVA with the between-subjects variable of group (CHF, control), and the within-subject variables of PM task (regular, irregular) and $P M$ cue (event-based, time-based). There was no main effect of group, PM task, or PM cue (all $F \mathrm{~s} \leq 1.77$; ps $\geq .270$ ). Group, however, interacted with $P M$ task $(F(1,41)=7.89$; $\left.p=.008 ; \eta_{\mathrm{p}}^{2}=.16\right)$. Tests of simple effects showed that for irregular tasks the CHF group $(M=.66 ; S D=.31)$ matched fewer tasks correctly than controls $(M=.86 ; S D=.31)$, $\left(F(1,41)=6.58 ; p=.014 ; \eta_{\mathrm{p}}^{2}=.14\right)$, but group did not differ for regular tasks $(F=.20 ; p=.657)$. Further tests of simple effects showed that for the CHF group, matching was worse for irregular $(M=.66 ; S D=.31)$ than for regular tasks $(M=.84 ; S D=.31),\left(F(1,41)=7.58 ; p=.009 ; \eta_{\mathrm{p}}{ }^{2}\right.$ $=.16$ ) but, for the control group, performance did not differ between regular and irregular tasks $(F=1.28 ; p=.265)$. Table 4 displays descriptive statistics for the proportion of correct matching of PM task and PM cue. It can be seen that the control group's performance was consistent across task type, whereas performance for the CHF group varied, with 
Table 4. Recognition of PM task content: Mean and $S D$ proportion of PM task and PM cue pairs matched correctly

\begin{tabular}{lccccc}
\hline \hline & \multicolumn{2}{c}{ CHF group $n=19^{\mathrm{a}}$} & & \multicolumn{2}{c}{ Control group $n=24^{\mathrm{a}}$} \\
\cline { 2 - 3 } \cline { 5 - 6 } PM task content & $M$ & $S D$ & & $M$ & $S D$ \\
\hline Regular event & .84 & .33 & & .80 & .38 \\
Regular time & .83 & .31 & & .79 & .38 \\
Irregular event & .78 & .28 & & .85 & .32 \\
Irregular time & .55 & .32 & & .86 & .30 \\
Overall & .75 & .20 & & .83 & .25 \\
\hline \hline
\end{tabular}

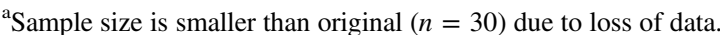

the lowest proportion of tasks matched correctly on irregular time tasks.

\section{Analyses of Shared Variance}

Exploratory analyses were then conducted to examine the potential role of other cognitive processes in the observed group difference on the proportion of missed PM tasks. Six $2 \times 2 \times 2$ mixed analyses of covariance (ANCOVAs) were conducted with the between subjects variable of group $(\mathrm{CHF}$, controls), and the within subjects variable of PM task (regular, irregular) and $P M$ cue (event, time), and one of the following variables entered as a covariate in each ANCOVA: cognitive inhibition, cognitive initiation, verbal memory (immediate recall), verbal memory (recognition), global cognition, and memory for task content. The dependent variable was the proportion of missed responses. Results showed that the small effect size $\left(\eta_{\mathrm{p}}{ }^{2}=.07\right)$ in the original ANOVA was reduced by a small amount following entry of each covariate. Specifically, the effect size $\left(\eta_{\mathrm{p}}{ }^{2}\right)$ dropped to .05 (cognitive inhibition and initiation), .04 (recognition), .03 (global cognition), .02 (immediate recall), and .02 (memory for task content). Thus, whilst each of these measures individually covaried with the PM deficit observed in the CHF group, global cognition, immediate recall (verbal memory), and memory for task content appeared to covary more than either of the two executive functions. Covarying for each of these variables reduced the statistical significance of the group main effect (all $p \mathrm{~s}>.103$ ). Out of interest, we also covaried cognitive flexibility and working memory (even though they did not significantly differ between groups in univariate analyses) but found that, as with other executive function measures, the degree of covariation was not substantial.

\section{Analysis of CHF Severity and Missed Prospective Memory Responses}

On the basis of the NYHA scale, participants were classified into low CHF severity (Class I and II; $n=21$ ), and high CHF severity (Class III and IV; $n=9$ ). Exploratory analysis of prospective memory performance revealed a non-significant trend, $t(28)=1.38, p=.178, d=.51$, toward more missed PM responses by the high severity group $(M=.35 ; S D=.30)$ compared to the low CHF severity group $(M=.22 ; S D=.20)$.

\section{DISCUSSION}

Although a large body of literature has shown that people with CHF present with deficits in a range of cognitive abilities (Pressler, 2008; Vogels, Scheltens, et al., 2007), this is the first empirical assessment of PM function in people with $\mathrm{CHF}$ relative to controls. Results indicated that the $\mathrm{CHF}$ group exhibited generalized PM impairment, with significant and similar sized deficits evident across all task parameters assessed (event, time, regular, irregular). These findings are consistent with studies that have used Virtual Week to examine PM in other clinical groups who are affected by both localized and diffuse neurological brain pathology, including people with multiple sclerosis, schizophrenia and other schizoaffective disorders, prior strokes, and long-term or acute substance use (Henry, Rendell, Kliegel, \& Altgassen, 2007; Kim, Craik, Luo, \& Ween, 2009; Rendell, Jensen, \& Henry, 2007; Terrett et al., 2014). While there is some variability in results across these different clinical groups, all show consistent deficits in PM, irrespective of specific PM task demands.

The poor PM performance of the CHF group does not appear to be a result of poor timing (i.e., it does not appear that $\mathrm{CHF}$ patients scored poorly because they performed PM tasks a little early or a little late). Rather, $\mathrm{CHF}$ patients missed more tasks altogether. However, there was also a nonsignificant trend suggesting that the $\mathrm{CHF}$ group completed fewer tasks at the correct moment. It is possible that this subtle trend might have reached statistical significance with a larger sample size.

The lack of variability in the CHF patients' impairment across PM task types suggests that the underlying cause of their poor PM performance cannot be explained entirely by retrospective memory deficits. Regular tasks in Virtual Week impose only minimal demands on retrospective memory (i.e., remembering what needs to be done) because the repeated presentation ensures they are well encoded. If the $\mathrm{CHF}$ participants' poor performance were solely a result of retrospective memory failure, PM performance should have been relatively weaker on the irregular tasks than on the regular tasks. Thus, these findings suggest the cause of the observed PM impairment involves the prospective component. Consistent with this idea, we found that when participants were asked what PM tasks they should have completed (at the end of each virtual day), they correctly recalled the content of around $80 \%$ of the PM tasks. This was the case for both groups. In other words, the CHF group was no worse than the control group at encoding what they had to do (i.e., the retrospective component), but had more difficulty initiating the PM tasks at the correct moments.

Although the $\mathrm{CHF}$ group in the current study was relatively high-functioning, in line with other literature, they did 
show deficits in several cognitive domains relative to controls, including cognitive inhibition, cognitive initiation, verbal memory (immediate recall and recognition), and global cognitive ability (Pressler, 2008; Vogels, Oosterman, et al., 2007; Vogels, Scheltens, et al., 2007). In contrast, no significant differences were observed on measures of cognitive flexibility, working memory, or delayed recall, although there was a consistent trend toward poorer performance by the CHF group.

Exploratory analyses examining the potential influence of these other cognitive abilities showed that the group difference in episodic memory overlapped substantially with the group difference in PM performance. This pattern was observed when using an established verbal memory tests (RAVLT) and also when participants' memory for the specific Virtual Week tasks content was assessed. Thus, while the primary analyses implicate a deficit in the prospective component for the CHF group, these further analyses highlight that retrospective memory is also important. Interestingly, executive functions and working memory had a more modest impact on the group differences in PM. However, interpretation of ANCOVAs requires caution in a nonrandomized study because the loss of statistical significance may reflect loss of power (Miller \& Chapman, 2001). For this reason, we focused on effect sizes rather than statistical significance, but even so, these findings require replication before firm conclusions can be drawn.

Although the ANCOVA findings need to be interpreted cautiously, they suggest that the CHF group's poorer retrospective memory may have influenced PM performance to a greater degree than executive functions. However, the lack of difference in PM performance between regular and irregular tasks in the original ANOVA suggests that residual variance is attributable to a separable prospective component. Thus, taken together, the findings indicate that difficulties with retrospective memory contribute to, but do not fully explain, the deficits observed in the prospective component, or the failure to initiate an action even after the intended action had been committed to memory. Interestingly, a similar pattern was observed in a study involving people with dementia and mild cognitive impairment (Thompson, Henry, Rendell, Withall, \& Brodaty, 2010).

CHF participants in the present study were relatively high functioning. Specifically, people with indicators of dementia were excluded, and $70 \%$ of the sample had no, or only mild, heart failure symptoms. In addition, subjective ratings of depression which, in other studies has been shown to contribute to PM impairment (Kliegel et al., 2005; Li, Weinborn, Loft, \& Maybery, 2013), were within the normal range. Thus, in the wider population of patients with $\mathrm{CHF}$, where medical and emotional symptoms are often more severe, PM failures are likely to be more pronounced.

A strength of this study is that participants with CHF were well characterized and were closely matched to the control group on important demographic variables (demographics, estimated IQ, and depression). However, some limitations must be acknowledged. The secondary analyses focusing on memory for task content had a reduced sample size and may have been underpowered to detect group differences. In addition, because of the cross-sectional nature of the study, it was not possible to establish whether the PM deficits existed before, or are the results of CHF. We found a promising nonsignificant trend toward better PM performance by patients with low CHF severity compared to high severity. However, as most participants were high functioning this analysis was underpowered, with too few participants $(n=9)$ in the high severity $\mathrm{CHF}$ group. Another related limitation was that $\mathrm{CHF}$ characteristics were assessed on recruitment, but were not reassessed at time of testing (typically 3 months later). Thus, cardiac severity was not entirely clear, and it may have changed for the better over time with medical management. Future studies are, therefore, needed to investigate whether measures of CHF severity (NYHA classification, Brain Natriuretic Peptide assays), are directly associated with PM performance.

Although preliminary, these data have clear clinical relevance. A key strategy within CHF management programs is to encourage patients to perform specific self-care behaviors to maintain clinical stability and recognize and respond early to changes in clinical symptoms (Riegel, Lee, \& Dickson, 2011). Key behaviors include medication adherence, fluid and sodium restrictions, daily weighing to monitor and recognize edema, and then, in the cases of symptom changes, responding by altering fluid intake or diuretic use (Riegel et al., 2011). However, despite the considerable emphasis in clinical practice on promoting CHF self-care, many patients have low success in completing self-care plans (Clark et al., 2014; Jaarsma et al., 2013). The present findings raise the possibility that PM difficulties may be contributing to poor self-care.

In conclusion, in this group of high functioning CHF patients, PM capacity was found to be impaired across all aspects of PM. If these preliminary findings are confirmed in larger studies, then strategies to increase self-care adherence within the CHF population may need to include PM training (Zogg, Woods, Sauceda, Wiebe, \& Simoni, 2012).

\section{ACKNOWLEDGMENTS}

The authors are grateful to the heart failure nurses across Eastern Health who generously assisted with recruitment. We acknowledge the help of Trevor Daniels in programming Virtual Week, and Mollie Flood in recruiting and testing some of the participants. The study was funded by a Mona Menzies Post-Doctoral Nursing Research Grant from the Nurses Board Victoria Legacy Ltd (J.C., C.S., \& D.T., grant number 0980022017), Discovery Project Grant from the Australian Research Council (P.R., grant number DP110100652), and an Australian Postgraduate Award scholarship (T.H). There are no conflicts of interest to declare.

\section{REFERENCES}

Almeida, O.P., Garrido, G.J., Beer, C., Lautenschlager, N.T., Arnolda, L., \& Flicker, L. (2012). Cognitive and brain changes associated with ischaemic heart disease and heart failure. 
European Heart Journal, 33, 1769-1776. doi:10.1093/eurheartj/ ehr467

Alosco, M.L., Spitznagel, M.B., Raz, N., Cohen, R., Sweet, L.H., Colbert, L.H., ... Gunstad, J. (2013). Executive dysfunction is independently associated with reduced functional independence in heart failure. Journal of Clinical Nursing, 23, 829-836. doi:10.1111/jocn. 12214

Artero, S., Tiemeier, H., Prins, N.D., Sabatier, R., Breteler, M.M.B., \& Ritchie, K. (2004). Neuroanatomical localisation and clinical correlates of white matter lesions in the elderly. Journal of Neurology, Neurosurgery, \& Psychiatry, 75, 1304-1308. doi:10.1136/jnnp.2003.023713

Bennett, S.J., \& Sauvé, M.J. (2003). Cognitive deficits in patients with heart failure: A review of the literature. Journal of Cardiovascular Nursing, 18. Retrieved from http://journals. lww.com/jcnjournal/Fulltext/2003/07000/Cognitive_Deficits_in_ Patients_With_Heart_Failure_.7.aspx

Braunwald, E. (2013). Heart failure. Journal of the American College of Cardiology: Heart Failure, 1(1), 1-20. doi: doi:10.1016/j.jchf.2012.10.002

Braver, T.S., \& Barch, D.M. (2002). A theory of cognitive control, aging cognition, and neuromodulation. Neuroscience \& Biobehavioral Reviews, 26, 809-817. doi:10.1016/S0149-7634(02) 00067-2

Bui, A.L., Horwich, T.B., \& Fonarow, G.C. (2010). Epidemiology and risk profile of heart failure. Nature Reviews Cardiology, 8, 30-41. doi:10.1038/nrcardio.2010.165

Burgess, P.W., \& Shallice, T. (1996). Response suppression, initiation and strategy use following frontal lobe lesions. Neuropsychologia, 34, 263-272. doi:10.1016/0028-3932(95) 00104-2

Cameron, J., Worrall-Carter, L., Page, K., Riegel, B., Lo, S.K., \& Stewart, S. (2010). Does cognitive impairment predict poor selfcare in patients with heart failure? European Journal of Heart Failure, 12, 508-515. doi:10.1093/eurjhf/hfq042

Clark, A.M., Spaling, M., Harkness, K., Spiers, J., Strachan, P.H., Thompson, D.R., \& Currie, K. (2014). Determinants of effective heart failure self-care: A systematic review of patients' and caregivers' perceptions. Heart, 100, 716-721. doi:10.1093/ eurjhf/hfp058

Cohen, J. (1988). Statistical power analysis for the behavioral sciences. Hillsdale, NJ: Lawrence Erlbaum.

Costa, A., Caltagirone, C., \& Carlesimo, G. (2011). Prospective memory impairment in mild cognitive impairment: An analytical review. Neuropsychology Review, 21, 390-404. doi:10.1007/s11065-011-9172-z

de Leeuw, F.E., de Groot, J.C., Achten, E., Oudkerk, M., Ramos, L.M.P., Heijboer, R., ... Breteler, M.M.B. (2001). Prevalence of cerebral white matter lesions in elderly people: A population based magnetic resonance imaging study. The Rotterdam scan study. Journal of Neurology, Neurosurgery, \& Psychiatry, 70, 9-14. doi:10.1136/jnnp.70.1.9

Einstein, G.O., \& McDaniel, M.A. (2005). Prospective memory: Multiple retrieval processes. Current Directions in Psychological Science, 14, 286-290. doi:10.1111/j.0963-7214.2005.00382.x

Ellis, J.A., \& Freeman, J.E. (2008). Prospective memory: Cognitive, neuroscience, developmental, and applied perspectives. Mahwah, NJ: Lawrence Erlbaum.

Foster, E.R., Rose, N.S., McDaniel, M.A., \& Rendell, P.G. (2013). Prospective memory in Parkinson disease during a Virtual Week: Effects of both prospective and retrospective demands. Neuropsychology, 27, 170-181. doi:10.1037/a0031946
Habota, T., Cameron, J., McLennan, S.N., Ski, C.F., Thompson, D.R., \& Rendell, P.G. (2013). Prospective memory and chronic heart failure. BMC Cardiovascular Disorders, 13, 63-71. doi:10.1186/1471-2261-13-63

Henry, J.D., Rendell, P.G., Kliegel, M., \& Altgassen, M. (2007). Prospective memory in schizophrenia: Primary or secondary impairment? Schizophrenia Research, 95, 179-185. doi:10.1016/ j.schres.2007.06.003

Jaarsma, T., Strömberg, A., Ben Gal, T., Cameron, J., Driscoll, A., Duengen, H.-D., . . . Riegel, B. (2013). Comparison of self-care behaviors of heart failure patients in 15 countries worldwide. Patient Education and Counseling, 92, 114-120. doi:10.1016/j. pec.2013.02.017

Kalaria, R.N., Kenny, R.A., Ballard, C.G., Perry, R., Ince, P., \& Polvikoski, T. (2004). Towards defining the neuropathological substrates of vascular dementia. Proceedings of the First Congress of the International Society for Vascular Behavioural and Cognitive Disorders (VAS-COG 2003), 226, 75-80. doi:10.1016/j.jns.2004.09.019

Kim, H.J., Craik, F.I.M., Luo, L., \& Ween, J.E. (2009). Impairments in prospective and retrospective memory following stroke. Neurocase, 15, 145-156. doi:10.1080/13554790802709039

Kindermann, I., Fischer, D., Karbach, J., Link, A., Walenta, K., Barth, C., ... Böhm, M. (2012). Cognitive function in patients with decompensated heart failure: The Cognitive Impairment in Heart Failure (CogImpair-HF) study. European Journal of Heart Failure, 14, 404-413. doi:10.1093/eurjhf/hfs015

Kliegel, M., Jäger, T., Phillips, L., Federspiel, E., Imfeld, A., Keller, M., \& Zimprich, D. (2005). Effects of sad mood on timebased prospective memory. Cognition and Emotion, 19, 1199-1213. doi:10.1080/02699930500233820

Krum, H., Jelinek, M.V., Stewart, S., Sindone, A., \& Atherton, J.J. (2011). 2011 update to National Heart Foundation of Australia and Cardiac Society of Australia and New Zealand Guidelines for the prevention, detection and management of chronic heart failure in Australia, 2006. The Medical Journal of Australia, 194, 405-409. Retrieved from https://www.mja. com.au/

Krum, H., Jelinek, M.V., Stewart, S., Sindone, A., Atherton, J.J., \& Hawkes, A.L. (2006). Guidelines for the prevention, detection and management of people with chronic heart failure in Australia 2006. Medical Journal of Australia, 185, 549-446. Retrieved from https://www.mja.com.au/

Lamberty, G.J., Putnam, S.H., Chatel, D.M., Bieliauskas, L.A., \& Adams, K.M. (1994). Derived Trail Making Test indices: A preliminary report. Cognitive and Behavioral Neurology, 7, 230-234. Retrieved from http://journals.lww.com/cogbehavneurol/ pages/default.aspx

Lindenfeld, J., Albert, N., Boehmer, J., Collins, S., Ezekowitz, J., Givertz, M., ... Walsh, M. (2010). HFSA 2010 Comprehensive Heart Failure Practice Guideline. Journal of Cardiac Failure, 16, e1-194. doi:10.1016/j.cardfail.2010.04.004

Li, Y.R., Weinborn, M., Loft, S., \& Maybery, M. (2013). Patterns of prospective memory impairment among individuals with depression: The influence of cue type and delay interval. Journal of International Neuropsychological Society, 19, 718-722. doi:10.1017/S1355617713000180

Lloyd-Jones, D.M., Larson, M.G., Leip, E.P., Beiser, A., D’Agostino, R.B., Kannel, W.B., ... Levy, D. (2002). Lifetime risk for developing congestive heart failure: The Framingham heart study. Circulation, 106, 3068-3072. doi:10.1161/01.CIR.0000039105. 49749.6F 
Mathuranath, P.S., Nestor, P.J., Berrios, G.E., Rakowicz, W., \& Hodges, J.R. (2000). A brief cognitive test battery to differentiate Alzheimer's disease and frontotemporal dementia. Neurology, $55,1613-1620$.

McDaniel, M.A., \& Einstein, G.O. (2000). Strategic and automatic processes in prospective memory retrieval: A multiprocess framework. Applied Cognitive Psychology, 14, S127-S144. doi:10.1002/acp.775

Miller, G.A., \& Chapman, J.P. (2001). Misunderstanding analysis of covariance. Journal of Abnormal Psychology, 110, 40-48. doi:10.1037//0021-843X.110.1.40

Nelson, H.E. (1982). National Adult Reading Test (NART): Test Manual. Windsor: NFER.

Pressler, S.J. (2008). Cognitive functioning and chronic heart failure: A review of the literature (2002-July 2007). Journal of Cardiovascular Nursing, 23, 239-249. doi:10.1097/01. JCN.0000305096.09710.ec

Pressler, S.J., Kim, J., Riley, P., Ronis, D.L., \& Gradus-Pizlo, I. (2010). Memory dysfunction, psychomotor slowing, and decreased executive function predict mortality in patients with heart failure and low ejection fraction. Journal of Cardiac Failure, 16, 750-760. doi:10.1016/j.cardfail.2010.04.007

Reitan, R.M. (1992). Trail Making Test: Manual for administration and scoring. Tucson, AZ: Reitan Neuropsychology Laboratory.

Rendell, P.G., \& Craik, F.I.M. (2000). Virtual week and actual week: Age-related differences in prospective memory. Applied Cognitive Psychology, 14, S43-S62. doi:10.1002/acp.770

Rendell, P.G., \& Henry, J.D. (2009). A review of Virtual Week for prospective memory assessment: Clinical implications. Brain Impairment, 10, 14-22. doi:http://dx.doi.org/10.1375/brim.10.1.14

Rendell, P.G., Jensen, F., \& Henry, J.D. (2007). Prospective memory in multiple sclerosis. Journal of the International Neuropsychological Society, 13, 410-416. doi:10.1017/S1355617707070579

Rey, A. (1958). L'examen clinique en psychologie. Oxford, England: Presses Universitaries De France.

Reynolds, J.R., West, R., \& Braver, T. (2009). Distinct neural circuits support transient and sustained processes in prospective memory and working memory. Cerebral Cortex, 19, 1208-1221. doi:10.1093/cercor/bhn164

Riegel, B., Lee, C.S., \& Dickson, V. (2011). Self care in patients with chronic heart failure. Nature Reviews Cardiology, 19, 644-654. doi:10.1038/nrcardio.2011.95

Rose, N.S., Rendell, P.G., McDaniel, M.A., Aberle, I., \& Kliegel, M. (2010). Age and individual differences in prospective memory during a "Virtual Week": The roles of working memory, vigilance, task regularity, and cue focality. Psychological Aging, 25, 595-605. doi:10.1037/a0019771
Terrett, G., McLennan, S.N., Henry, J.D., Biernacki, K., Mercuri, K., Curran, H.V., \& Rendell, P.G. (2014). Prospective memory impairment in long-term opiate users. Psychopharmacology, 231, 2623-2632. doi:10.1007/s00213-014-3432-6

Thompson, C., Henry, J.D., Rendell, P.G., Withall, A., \& Brodaty, H. (2010). Prospective memory function in mild cognitive impairment and early dementia. Journal of the International Neuropsychological Society, 16, 318-325. doi:10.1017/ S1355617709991354

Vogels, R.L.C., Oosterman, J.M., Van Harten, B., Scheltens, P., Van Der Flier, W.M., Schroeder-Tanka, J.M., \& Weinstein, H.C. (2007). Profile of cognitive impairment in chronic heart failure. Journal of the American Geriatrics Society, 55, 1764-1770. doi:10.1111/j.1532-5415.2007.01395.x

Vogels, R.L.C., Scheltens, P., Schroeder-Tanka, J.M., \& Weinstein, H.C. (2007). Cognitive impairment in heart failure: A systematic review of the literature. European Journal of Heart Failure, 9, 440-449. doi:10.1016/j.ejheart.2006.11.001

Vogels, R.L.C., van der Flier, W.M., van Harten, B., Gouw, A.A., Scheltens, P., Schroeder-Tanka, J.M., \& Weinstein, H.C. (2007). Brain magnetic resonance imaging abnormalities in patients with heart failure. European Journal of Heart Failure, 9, 1003-1009. doi:10.1016/j.ejheart.2007.07.006

Volz, A., Schmid, J.P., Zwahlen, M., Kohls, S., Saner, H., \& Barth, J. (2011). Predictors of readmission and health related quality of life in patients with chronic heart failure: A comparison of different psychosocial aspects. Journal of Behavioural Medicine, 34, 13-22. doi:10.1007/s10865-010-9282-8

Wechsler, D. (2008). Wechsler Adult Intelligence Scale-Fourth Edition (WAIS-IV). San Antonio, TX: Pearson.

Woo, M.A., Macey, P.M., Fonarow, G.C., Hamilton, M.A., \& Harper, R.M. (2003). Regional brain gray matter loss in heart failure. Journal of Applied Physiology, 95, 677-684. doi:10.1152/ japplphysiol.00101.2003

Zigmond, A.S., \& Snaith, R.P. (1983). The Hospital Anxiety and Depression Scale. Acta Psychiatrica Scandinavica, 67, 361-370. doi:10.1111/j.1600-0447.1983.tb09716.x

Zogg, J., Woods, S., Sauceda, J., Wiebe, J., \& Simoni, J. (2012). The role of prospective memory in medication adherence: A review of an emerging literature. Journal of Behavioral Medicine, 35, 47-62. doi:10.1007/s10865-011-9341-9

Zuccalà, G., Cattel, C., Manes-Gravina, E., Di Niro, M.G., Cocchi, A., \& Bernabei, R. (1997). Left ventricular dysfunction: A clue to cognitive impairment in older patients with heart failure. Journal of Neurology, Neurosurgery, \& Psychiatry, 63, 509-512. doi:10.1136/jnnp.63.4.509 